\title{
Sustainable development of housing construction in a major city due to the standard- class segment
}

\author{
Aleksey Pestryakov, Nadezhda Sbrodova Alisa Titovets, and Polina Pysova \\ Ural State University of Economics, 620144 Yekaterinburg, Russia
}

\begin{abstract}
Within the framework of achieving several sustainable development goals, the construction of high-quality and affordable housing for citizens is considered. According to the Decree of the President of the Russian Federation "On national goals and strategic objectives of the development of the Russian Federation for the period up to 2030", it is necessary to increase the volume of housing construction to at least 120 million square meters per year. The construction of standard-class housing contributes to the achievement of these goals. The article uses regression analysis to determine the main factors affecting the construction of standard-class housing in the city of Yekaterinburg. The problems and prospects for the development of housing construction at the expense of the standard-class segment are also identified.
\end{abstract}

\section{Introduction}

The availability of housing for the population can be attributed to indicators directly proportional to the level of socio-economic development of the country, so the availability of housing has been and remains one of the main tasks of the authorities in the field of housing development [1], [2]. In addition, within the framework of the concept of sustainable development and the achievement of the Sustainable Development Goals, the construction of affordable and high-quality housing is one of the main directions of the development of the territory and the economy. Housing is a basic human need and therefore contributes to the achievement of the following Sustainable Development Goals: the universal elimination of poverty in all its forms (SDG 1); the promotion of sustained, inclusive and sustainable economic growth, full and productive employment and decent work for all (SDG 8); and the openness, security, resilience and environmental sustainability of cities and human settlements (SDG 11) [3,4,5].

Housing construction involves the creation of residential buildings and structures, with apartments and rooms included in them [6]. Standard-class residential real estate refers to the cheapest housing in the class of new buildings, which is aimed at young families with low or average earnings, as well as single citizens. The main criteria of this class, 
developed by the Russian Guild of Realtors (hereinafter-RSG) and the Ural Chamber of Real Estate (hereinafter-UPN), are [7], [8]:

- apartments with a standard layout, located in standard serial projects (most often reused) of multi-storey buildings with turnkey finishing»;

- on one floor there are up to 12 rooms with small areas with a predominance of oneroom apartments and studios of small area (about 30 sq. m.). m); the ceiling height of apartments is less than $2.7 \mathrm{~m}$;

- standard engineering support of houses: central heating, electricity supply according to the norms;

- a standard-class residential building has a typical appearance without special architectural solutions;

- the house territory meets the standards. It can be either fenced or not fenced, and there is also a ground parking where the number of cars meets the standards.

The main task of developers operating in the "standard" class is to reduce the cost of housing construction as much as possible while maintaining compliance with legally established standards. This explains the use of inexpensive materials in construction. In addition, developers most often build standard-class housing on the outskirts of the city, in "residential areas", reducing the area of apartments, but increasing their number.

\section{Materials and Methods}

The development of housing construction at the expense of the standard-class segment is influenced by various factors. It is proposed to identify the existing relationships by constructing a pair correlation-regression model. This model helps to rank and determine the key factors that have the greatest impact on the development of housing construction at the expense of standard-class residential real estate.

The most important thing when building a model is the choice of basic indicators. To do this, we will follow the basic rules [9]:

- $\quad$ the baselines should be linked by cause and effect;

- $\quad$ when building a model, it is necessary to select the most significant factors;

- the relationship of factors should not be curved.

Standard-class housing is the most affordable housing for the population, the target audience of which is young families with children, visitors from remote areas, single people. According to this definition, the authors selected indicators for constructing a multifactor correlation model of the volume of input of standard-class residential real estate in the city of Yekaterinburg (Table 1).

Table 1. Factors for constructing a multi-factor correlation model of the volume of input of standardclass residential real estate in the city of Yekaterinburg, 2013-2020.

\begin{tabular}{|c|c|c|c|c|c|c|c|c|}
\hline Factor & 2013 & 2014 & 2015 & 2016 & 2017 & 2018 & 2019 & 2020 \\
\hline $\begin{array}{c}\text { Price of 1 sq. m. m } \\
\text { of standard-class } \\
\text { housing in } \\
\text { Yekaterinburg, } \\
\text { rubles (X1) }\end{array}$ & 56800 & 54700 & 55800 & 56405 & 57310 & 58134 & 62900 & 67300 \\
\hline $\begin{array}{c}\text { Number of citizens in } \\
\text { need of housing in } \\
\text { Yekaterinburg, units } \\
\text { (X2) }\end{array}$ & 15349 & 15340 & 15147 & 14577 & 15050 & 11387 & 11450 & 11523 \\
\hline
\end{tabular}


Table 1. Continued

\begin{tabular}{|c|c|c|c|c|c|c|c|c|}
\hline $\begin{array}{c}\text { Real salary in } \\
\text { Yekaterinburg in } \\
\text { prices of 2013, rubles } \\
\text { (X3) }\end{array}$ & 37190 & 39644 & 41015 & 43910 & 46109 & 49222 & 53326 & 53262 \\
\hline $\begin{array}{c}\text { Population in } \\
\text { Yekaterinburg, } \\
\text { thousand people (X4) }\end{array}$ & 1445,7 & 1461,4 & 1477,7 & 1477,7 & 1488,4 & 1515,8 & 1526,4 & 1527,0 \\
\hline $\begin{array}{c}\text { Number of registered } \\
\text { marriages in } \\
\begin{array}{c}\text { Yekaterinburg, units } \\
\text { (X5) }\end{array}\end{array}$ & 12555 & 12690 & 13161 & 11274 & 11708 & 9959 & 10853 & 6625 \\
\hline $\begin{array}{c}\text { Total area of houses } \\
\text { recognized as } \\
\text { dilapidated and } \\
\text { dilapidated in } \\
\text { Yekaterinburg, sq. m } \\
\text { (X6) }\end{array}$ & 8837,3 & 6165,6 & 11120,2 & 7182,3 & 10387,8 & 9992,5 & 10537,5 & 11292,5 \\
\hline $\begin{array}{c}\text { Migration growth } \\
\text { (decrease) of the } \\
\text { population, people } \\
\text { (X7) }\end{array}$ & 11800 & 11182 & 9580 & 4808 & 9138 & 11232 & 9195 & 2968 \\
\hline
\end{tabular}

The selected factors must be reliable and homogeneous, so it is necessary to analyze them and exclude those that do not meet the sample conditions. The uniformity of the information can be checked using criteria such as the standard deviation and the coefficient of variation:

$$
\begin{aligned}
& S(x)=\sqrt{\frac{\sum(x-\bar{x})^{2}}{n}} \\
& K=\frac{S(x) \cdot 100}{\bar{x}}
\end{aligned}
$$

The coefficient of variation is evaluated on a scale: minor variation-the coefficient does not exceed $10 \%$; average variation-the coefficient is $10 \%-20 \%$; significant-the variation is 20\%-33\%. Variation over 33\% should be excluded, as it will not be uniform. The calculation results are shown in Table 2 .

Table 2. Results of the calculation of the standard deviation and the coefficient of variation

\begin{tabular}{|c|c|c|c|}
\hline Indicator & Arithmetic mean & Standard deviation & Variation, \% \\
\hline$Y$ & 552,18 & 98,09 & 17,76 \\
\hline$X 1$ & 58668,63 & 3986,41 & 6,79 \\
\hline$X 2$ & 13727,88 & 1776,23 & 12,94 \\
\hline$X 3$ & 45459,75 & 5719,47 & 12,58 \\
\hline$X 4$ & 1493,01 & 28,19 & 1,89 \\
\hline$X 5$ & 11103,13 & 1958,35 & 17,64 \\
\hline$X 6$ & 9439,46 & 1762,28 & 18,67 \\
\hline$X 7$ & 8737,88 & 2987,15 & 34,19 \\
\hline
\end{tabular}


Table 2 shows that the coefficient of variation of the factor "Migration increase (decrease) of the population, person (X7)" exceeds 33\%. This indicator will be excluded from further analysis. All other factors will be included in the regression analysis.

The authors used Excel to construct a linear multivariate regression. The regression equation in its original form looks like:

$$
Y_{x}=b_{0}+b_{1} X_{1}+b_{2} X_{2}+\cdots+b_{n} X_{n}
$$

The coefficients $b$ show how the object under study will change if the factor value changes by one. To compile a multi-factor model, a matrix of paired correlation coefficients was compiled and the most significant factors for analysis were selected (Table 3).

Table 3. Matrix of paired correlation coefficients

\begin{tabular}{|c|c|c|c|c|c|c|c|c|}
\hline & $\mathrm{y}$ & $\mathrm{X} 1$ & $\mathrm{X} 2$ & $\mathrm{X} 3$ & $\mathrm{X} 4$ & $\mathrm{X} 5$ & $\mathrm{X} 6$ & $\mathrm{X} 7$ \\
\hline $\mathrm{Y}$ & 1 & $-0,92$ & 0,85 & $-0,83$ & $-0,74$ & 0,93 & $-0,37$ & 0,54 \\
\hline $\mathrm{X} 1$ & & 1 & $-0,79$ & 0,84 & 0,76 & $-0,88$ & 0,60 & $-0,62$ \\
\hline $\mathrm{X} 2$ & & & 1 & $-0,90$ & $-0,86$ & 0,79 & $-0,50$ & 0,31 \\
\hline $\mathrm{X} 3$ & & & & 1 & 0,98 & $-0,80$ & 0,57 & $-0,50$ \\
\hline $\mathrm{X} 4$ & & & & & 1 & $-0,75$ & 0,60 & $-0,50$ \\
\hline $\mathrm{X} 5$ & & & & & & 1 & $-0,42$ & 0,69 \\
\hline $\mathrm{X} 6$ & & & & & & & 1 & $-0,19$ \\
\hline $\mathrm{X} 7$ & & & & & & & & 1 \\
\hline
\end{tabular}

The most significant factors are those where the correlation coefficient between $\mathrm{Y}$ and $\mathrm{X}$ is equal to or greater than 0.85 modulo. These factors include:

- $\quad$ price of 1 sq. m. $m$ of standard-class housing in Yekaterinburg (X1);

- real wages in Yekaterinburg in 2013 prices (X3);

- the number of registered marriages in Yekaterinburg (X5).

It is worth noting that by studying the matrix of paired correlation coefficients, you can see a close relationship between the indicators. So, the relationship between the indicators in our case is strong (0.7-0.9) and very strong (0.9-0.99).

We proceed to the calculation of the coefficients $b$. To do this, use the formula:

$$
B=\left[[X]^{T} \cdot[X]\right]^{-1} \cdot\left[X^{T}\right] \cdot Y
$$

The calculation results are as follows: b0 is 906.8 ; b1 and b2 are -0.009 and -0.002 , respectively; b3 is 0.03 . The multiple pair regression equation has the form:

$$
\mathrm{Y}=906,8-0,009 \mathrm{X}_{1}-0,002 \mathrm{X}_{2}+0,03 \mathrm{X}_{3}
$$

Thus, we can conclude that with the growth of the price of 1 sq. m. $m$ of standard-class housing in Yekaterinburg per unit in absolute terms, the volume of commissioning of standard-class housing will decrease by 0.009 . With the growth of real wages, the volume will decrease by 0.002 . With an increase in the number of registered marriages, the volume of standard-class input will increase by 0.03 . The calculated $\mathrm{Y}$ value is shown in Table 4.

Table 4. Results of the calculation of the volume of input of standard-class housing

\begin{tabular}{|c|c|c|c|c|c|c|c|c|}
\hline $\begin{array}{c}\text { The volume of input of } \\
\text { standard-class } \\
\text { housing, thousand sq. } \\
\text { m (Y) }\end{array}$ & 585,5 & 624,8 & 706,2 & 582,8 & 576,8 & 510,86 & 470,47 & 360,00 \\
\hline Y estimated & 599,38 & 650,91 & 658,28 & 575,87 & 588,19 & 508,99 & 483,04 & 342,32 \\
\hline
\end{tabular}


The reliability of the calculations was confirmed using the Fischer test, calculated using the formula:

$$
F=\frac{\sum\left(y-\bar{y}_{p}\right)^{2}}{m} \cdot \frac{(n-m-1)}{\sum\left(y-y_{p}\right)^{2}}
$$

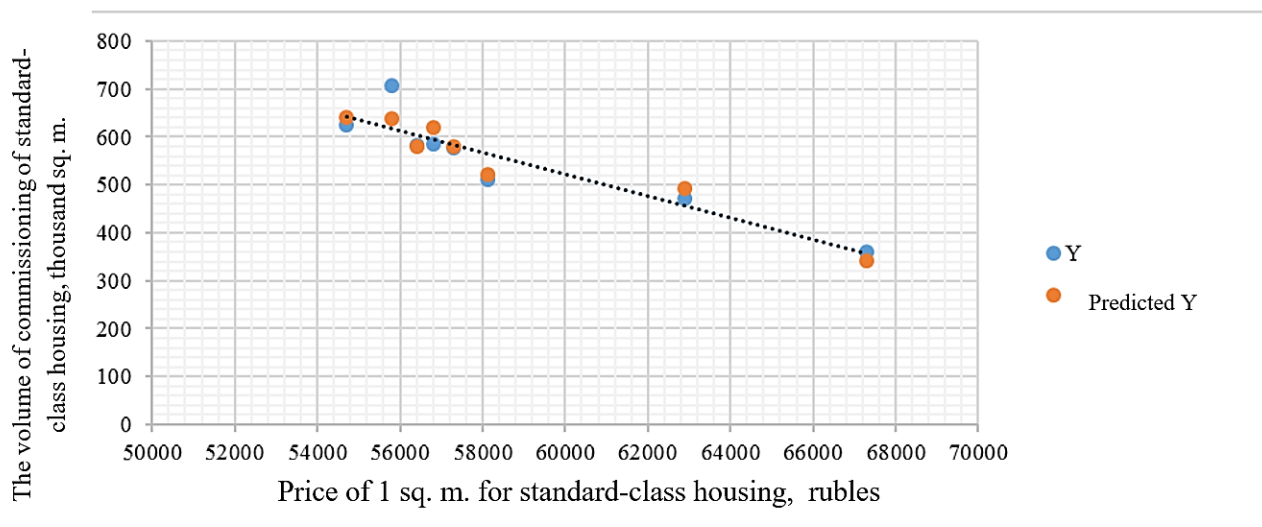

Fig. 1. The dependence of the volume of standard-class housing input on the price of $1 \mathrm{sq} . \mathrm{m}$. standard-class housing in Yekaterinburg

From this graph, it can be seen that with an increase in the price of housing, the volume of input decreases. Note that there is a spread of points on the graph, this is due to the fact that the sample size is small. Consider the relationship between Y and X2 (Figure 2).

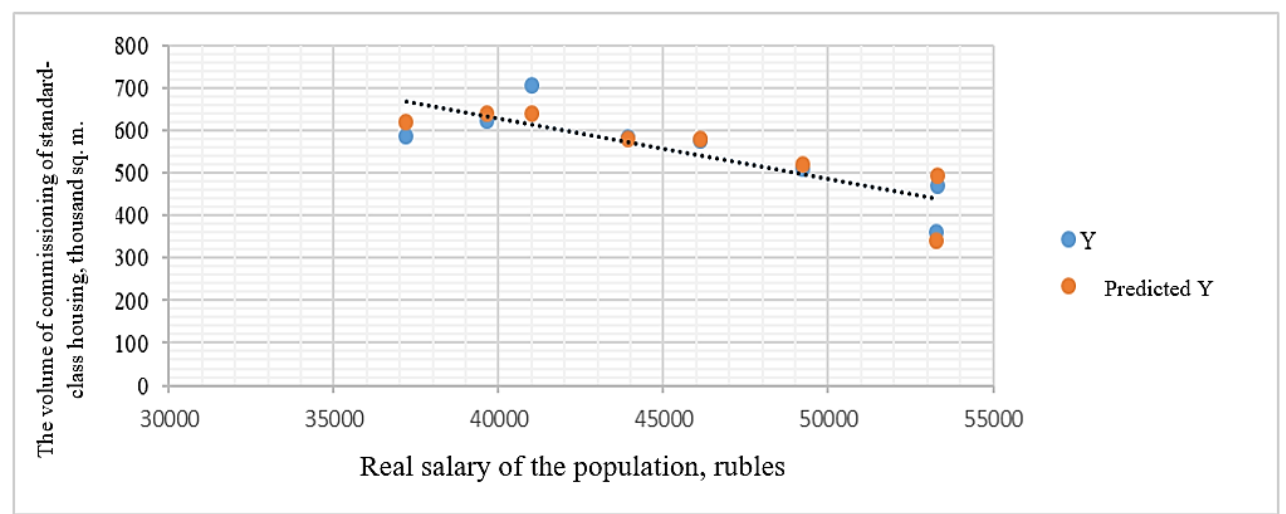

Fig. 2. Dependence of the volume of standard-class housing commissioning on the real salary of the population in Yekaterinburg

This graph shows that the growth of real wages leads to a decrease in the input of standard-class housing.

Let's consider the relationship between the volume of standard-class housing input and the number of registered marriages (Fig. 3). 


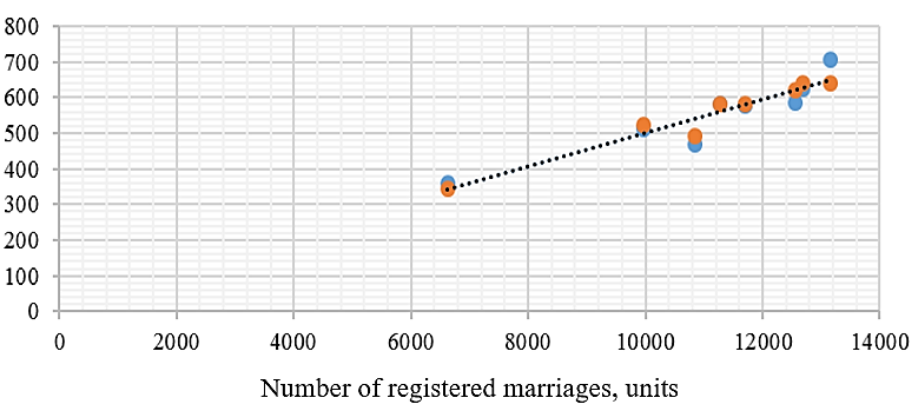

$\bullet Y$

- Predicted $Y$

Fig. 3. The dependence of the volume of input of standard-class housing on the number of registered marriages in Yekaterinburg

Figure 3 shows that the more registered marriages, the higher the volume of input of standard-class housing.

The regression analysis described above allowed the authors to conclude that the dynamics of construction of standard-class housing in Yekaterinburg is in line with the theoretical conceptual characteristics of this class of housing: the most significant factors are the price of 1 sq.m., real wages, the number of registered marriages.

\section{Results and Discussion}

The Sverdlovsk region is one of the top ten regions of the Russian Federation - leaders in terms of housing commissioning [10]. In turn, most of the new housing is concentrated in Yekaterinburg (92.1\%), as an active center of the region.

Despite the consistently large volumes of housing commissioning in Yekaterinburg (over 1 million sq. m. annually), the official statistics show a noticeable decrease in the share of standard class housing. It is obvious that this is due to an increase in the volume of commissioning of comfort-class housing (Fig. 4).

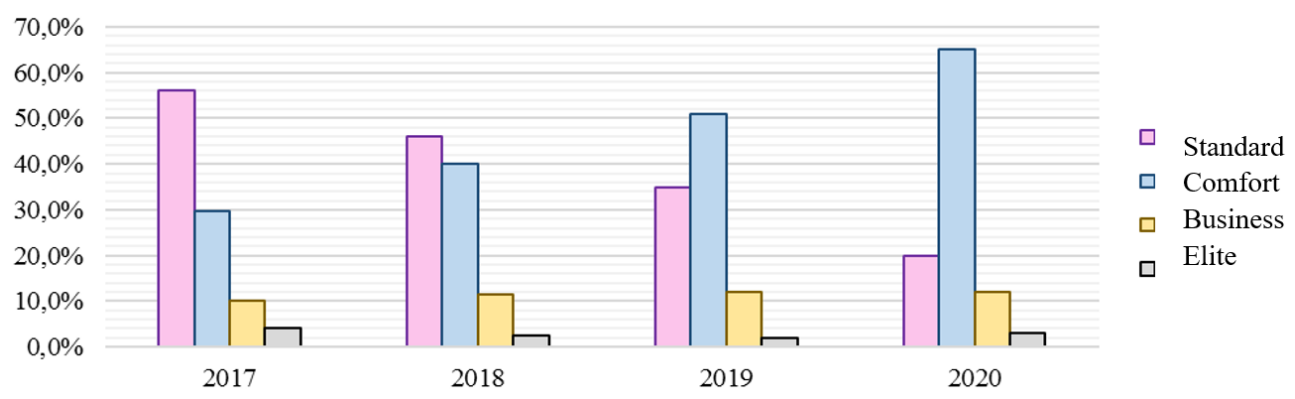

Fig. 4. Structure of residential real estate input by class in the city of Yekaterinburg, 2017-2020, \%

Comfort-class occupies more than half of the total volume of housing input in Yekaterinburg. The authors suggest that this situation is associated with the impact of both objective factors (the relatively high level of income of the population allows you to purchase higher-class housing) and subjective (developers overestimate the voiced class of housing to increase its attractiveness).

Note that the legislation does not have clear criteria that distinguish the division between classes [11]. The authors evaluated a number of standard - and comfort-class residential complexes according to the main criteria of the Ural Chamber of Real Estate 
(number of apartments per floor; interior wall decoration; apartment area; ceiling height; wall material) to determine whether the declared characteristics meet the formal requirements. As a result, it was revealed that $56 \%$ of residential complexes declared in advertising as comfort class do not meet the criteria. The most common inconsistencies include the understated area of apartments relative to the standards, low ceiling height, a large number of apartments on the floor.

Thus, the actual volume of construction of standard-class housing in Yekaterinburg significantly exceeds the official data.

The desire of developers to attribute the object to a higher class of "comfort"can also be explained by the complex reputation of standard-class housing. According to the Methodology for evaluating residential complexes developed by specialists of the Unified Register of Developers, the level of comfort is determined in points. Most standard-class houses in the city of Yekaterinburg have a low rating score, on average equal to 46.5 (out of 100 possible). This suggests that this housing can not be considered comfortable even within the declared class. Note that standard-class housing received the lowest number of points according to such criteria as:

- number of parking spaces;

- compliance with landscaping regulations;

- compliance with the design standards of playgrounds.

It is not surprising that the population has a negative attitude to standard-class housing.

Mass construction of standard-class residential complexes often ignores the need to create associated infrastructure [11]. The largest number of standard-class residential complexes are located on the outskirts of the city, in such microdistricts as Akademichesky, Shirokaya Rechka, ZhBI, Compressor and Vtorchermet. This fact also leads to a number of negative consequences, in particular, traffic congestion, lack of places in preschool and school institutions, lack of polyclinics within walking distance, etc.

The portrait of a standard-class home buyer is as follows [12]: a young family with an average or lower-average income, who works most often in the fields of trade, health and education; visitors from remote areas of the North; a single person, a student or a pensioner. There are buyers who seek to get passive income, so after buying a home, they rent it out. The sources of funds for the majority of the population who buy standard-class residential real estate are money from the sale of property, loans from relatives or mortgage financing.

The price of 1 sq. $\mathrm{m}$. in the market of standard-class residential real estate is $20 \%$ below the price of 1 sq. m. in general, in the primary housing market of Yekaterinburg, on average (Fig. 5). The price increase in 2019-2020 affected all housing classes. Many experts attribute it to the introduction of government programs and lower mortgage rates.

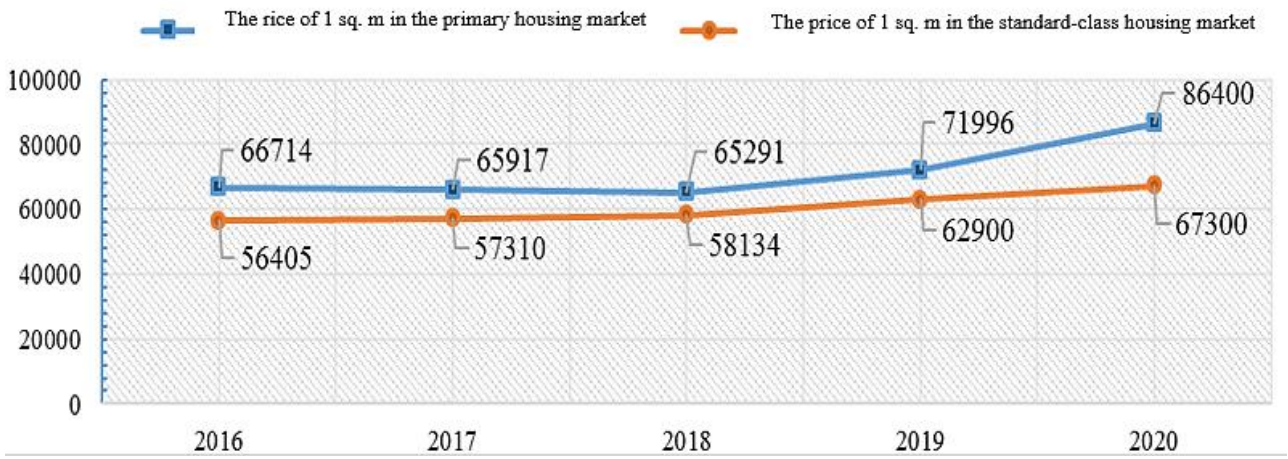

Fig. 5. Dynamics of price changes in 1 sq. $\mathrm{m} . \mathrm{m}$ in the standard-class housing market in Yekaterinburg, 2016-2020, rubles 
The authors calculated the coefficient of affordability of standard-class housing in Yekaterinburg using the formula:

$$
\mathrm{K}_{\mathrm{pa}}=\mathrm{w}_{\mathrm{i}} / \mathrm{p}_{\mathrm{i}} \times 100
$$

The formula allows you to estimate for what part of 1 sq. m. the average per capita income of the population will be enough for housing. The results of the calculation can be seen in Table 5.

Table 5. The coefficient of affordability of standard-class housing in the city of Yekaterinburg, 20162019

\begin{tabular}{|c|c|c|c|c|}
\hline Year & 2016 & 2017 & 2018 & 2019 \\
\hline Calculated availability factor & 98,7 & 106,1 & 88,7 & 87,4 \\
\hline
\end{tabular}

It should be noted that in 2019, in relation to 2016 , the housing affordability ratio in the standard-class housing market decreased by 11.3 percentage points, that is, housing in Yekaterinburg, even at the standard-class level, became less affordable for the population.

\section{Conclusions}

The analysis revealed the following problems that hinder the development of housing construction in Yekaterinburg at the expense of the standard-class segment:

- the division of housing into classes is not regulated at the legislative level;

- poor reputation of standard-class housing;

- stagnation of infrastructure development with large housing .

The problems depend on several categories of housing construction participants: the division of housing into classes, which is not regulated at the legislative level, depends on the federal authorities that have not included the criteria for standard-class housing in legislative acts; developers who violate the declared characteristics of residential complexes affect the bad reputation; also, developers, when designing a standard-class residential complex, do not take into account the quality of the surrounding infrastructure. Finally, the municipal authorities that issue building permits do not always monitor in detail the compliance of developers with the norms and do not ensure the development of infrastructure facilities in remote areas of the city.

The authors see the development of additional criteria for standard-class housing at the federal level as one of the ways to solve the problems. Additional criteria that must be included in the Order of the Ministry of Construction of the Russian Federation "On approval of the conditions for classifying residential premises as standard housing" are: design, construction solutions (number of floors, wall material); planning solutions (number of apartments per floor, apartment area, ceiling height); engineering systems (elevator, fence); landscaping of the house and yard territory.

The bad reputation of standard-class residential complexes can be eliminated if you make methodological recommendations developed by the HOUSE.The Russian Federation and the Ministry of Construction of the Russian Federation, mandatory for developers. To improve the quality of infrastructure, the authors suggest that developers and municipal authorities equip microdistricts in the largest cities of the regions with social and transport infrastructure. The implementation of the proposed recommendations will allow Russia to achieve better results in the implementation of the Sustainable Development Goals. 


\section{References}

1. A.V. Storozhilova, Economic science and practice: materials for the IV International Scientific Conference (2016)

2. A. S. Shirokov, Young Scientist, 12(92) (2015)

3. A. Sakharov, O. Kolmar, Journal of Research of International Organizations, 14(1), 189 (2019)

4. N. Winston, M. Parekha Eastway, Soc Indic Res, 87 (2008)

5. S. Ansell, M. Thompson-Fawcett, Housing research, 23(3) (2008)

6. A. Asaul, Real Estate Economics: A textbook for universities, 3rd ed. The thirdgeneration standard (2013)

7. Russian Guild of Managers and Developers, http://rgud.ru

8. Ural Chamber of Real Estate, http://upn.ru

9. N. V. Andreeva, M. Y. Chervyakova, Economic analysis: theory and practice, 37(340) (2013)

10. The official website of the Federal State Statistics Service, http://www.gks.ru

11. S. G. Zubanova, Housing construction, 1-2 (2018)

12. S. V. Alexandrovsky, E. V. Artyushina, D. A. Fomenkov, M. A. Shushkin, Housing construction? 8 (2020) 